\title{
PENGARUH NILAI ISLAM PADA VISUAL PAKAIAN DEWA DAN RESI BONEKA WAYANG JEKDONG JAWA TIMUR
}

\author{
Alfian Candra Ayuswantana ${ }^{1}$, Agus Sachari², Irfansyah ${ }^{3}$ \\ ${ }^{1}$ Program Studi DKV, Fakultas Arsitektur dan Desain, Universitas Pembangunan Nasional "Veteran" Jawa \\ Timur, 2, 3 Fakultas Seni Rupa dan Desain, Institut Teknologi Bandung \\ alfianayuswantana.dkv@upnjatim.ac.id ${ }^{1}$
}

\begin{abstract}
Abstrak
Wayang Jekdong hidup dan berkembang dalam konteks sosial-budaya Arek yang sangat khas. Budaya Arek sebagai sub-budaya Jawa Timur menyebar dari pantai utara Jawa Timur ke pedalaman sepanjang aliran sungai Brantas menyebabkan pengaruh nilai-nilai Islam kental terasa pada budaya Arek. Nilai-nilai Islam yang kuat salah satunya dapat dilihat dalam wayang boneka Jekdong sebagai artefak budaya masyarakat budaya Arek. Penelitian ini berfokus pada pengamatan visual pada boneka Jekdong yang mewakili nilai-nilai Islam melalui bentuk boneka. Pengamatan dilakukan dengan pendekatan etnografi melalui proses analisis komponen visual Spradley dalam wayang Jekdong yang didukung oleh teori semiotika dyadic Saussure-Barthes. Hasil analisis menunjukkan bahwa ada pengaruh nilai-nilai Islam yang diwakili dalam bentuk boneka wayang Jekdong terutama pada tokoh Dewa (dewa atau dewa tertinggi) dan Resi (pertapa). Bentuk budaya Arek sebagai komunitas Islam pesisir sangat jelas terlihat terutama pada atribut pakaian yang ditampilkan seperti keberadaan turban putih, khaftan, qamis, dan sepatu Persia. Diharapkan dengan penelitian ini dapat memberikan kontribusi ilmiah tentang wayang golek Jekdong dalam sudut pandang ilmiah seni di provinsi Jawa Timur khususnya.
\end{abstract}

Kata Kunci: budaya Arek, busana, wayang Jekdong, Islam pesisir

\begin{abstract}
The Jekdong puppets lives and develops in a very distinctive Arek socio-cultural context. The Arek culture as East Java sub-culture spreads from the north coast of East Java to the depths along with the Brantas river flow causing the influence of Islamic values upon the Arek Culture. Strong Islamic values, one of them can be seen within Jekdong puppets as a cultural artifact of the Arek society. This research focuses on visual observations on Jekdong puppets that represent Islamic values through the form of puppets. Observations performed with an ethnographic approach through a process of Spradley's visual components analyzing in Jekdong puppets and supported by the dyadic semiotics theory of Saussure-Barthes. The results of the analysis show that there are influences of Islamic values that represented in the form of Jekdong puppets, especially in Dewa (deity or supreme being) and Resi (hermits or saints) figures. The form of Arek culture as an Islamic coastal community is very clearly visible, especially in the fashion attributes that displayed such as the existence of white turban, Kaftan, Qamis, and Persian shoes. It expected that this research could provide scientific contributions about the Jekdong puppet show puppet in the scientific viewpoint of art, particularly in East Java province.
\end{abstract}

Keywords: Arek culture, coastal Islam, fashion, Jekdong puppet 


\section{PENDAHULUAN}

Wayang Jekdong merupakan bagian dari ragam kesenian wayang kulit yang berkembang di provinsi Jawa Timur khususnya pada lingkup budaya "Arek" yang meliputi Bojonegoro, Probolinggo, Situbondo, Lamongan, Gresik, Jombang, Mojokerto, Pasuruan, Surabaya, Malang, dan Sidoarjo (Christianto, 2012).

Kondisi geografis budaya Arek yang sebagian tersebar pada daerah pesisir utara pantai Jawa Timur mengkondisikan sebagai gerbang perlintasan perdagangan dan kebudayaan asing termasuk didalamnya sebagai pintu gerbang utama penyebaran Islam di bumi Jawa. Kota-kota bandar perdagangan di daerah pesisir utara Jawa Timur yang bercorak Islam antara lain; Surabaya sebagai poros kerajaan Islam abad XVII di Jawa Timur, Gresik sebagai pelabuhan internasional dan pusat keagamaan Islam dan Pasuruhan (Ricklefes, 2016: 58-59).

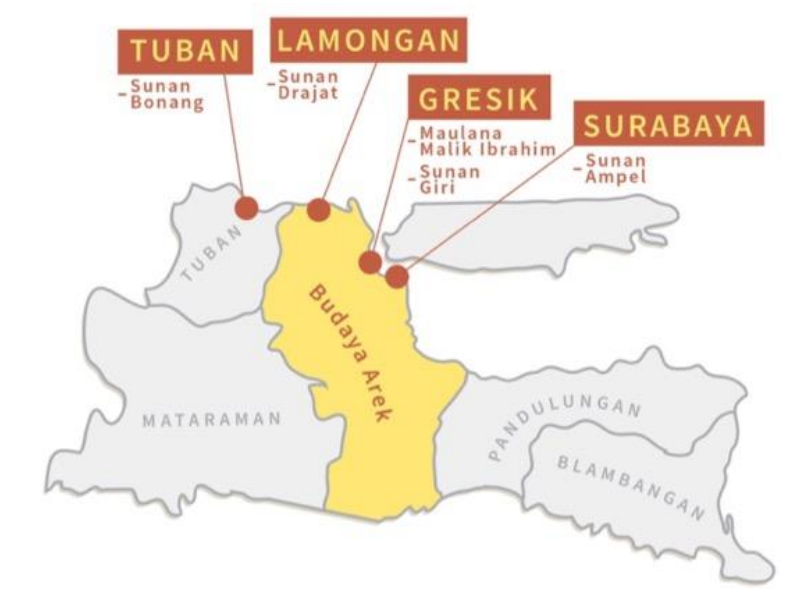

Gambar 1. Peta lima Wali Allah/Walisongo di Jawa Timur [Sumber: Sunyoto, 2016: 143]

Jawa Timur menempati posisi penting dalam proses Islamisasi di Jawa (Syam, 2005: 101). Hal tersebut dapat dilihat dari bukti-bukti sejarah mengenai banyaknya Wali Allah SWT penyebar Islam di daerah Jawa Timur, lima diantaranya menancapkan basis dakwah Islam di kota-kota sekitar pesisir utara Jawa Timur. Kelima Wali tersebut adalah Maulana Malik Ibrahim yang berpusat di Gresik sebuah kota pelabuhan bandar perdagangan internasional terbaik diseluruh Jawa pada masanya (Anshori \& Kusrianto, 2011: 3), Sunan Giri juga berpusat di Gresik, Sunan Ampel yang berpusat di Surabaya, Sunan Bonang yang berpusat di Tuban dan Sunan Drajat yang berpusat di Sidayu-Lamongan. Diantara Walisongo di atas merupakan wali dengan golongan Putihan yang menyebarkan dakwah Islam berdasarkan Al Quran dan Al Hadist tanpa melakukan sinkritisasi dengan ajaran nenek moyang Jawa (Aizid, 2015: 18). Syam (2005) melanjutkan mengapa posisi kota-kota pesisir seperti Surabaya, Tuban dan Gresik sebagai kota perdagangan yang besar dimanfaatkan oleh para Wali dalam menyebarkan Islamisasi, letak kota-kota pesisir memiliki kelebihan dimana kota-kota tersebut memiliki akses menjadi titik peleburan budaya, lalu lintas laut yang relatif lebih mudah dari pada daratan, dan karakter masyarakat pesisir yang lebih terbuka dari pada masyarakat pedalaman. 
Ruang lingkup budaya Arek yang beririsan dengan daerah pesisir utara Jawa Timur merupakan pusat-pusat Islamisasi sejak berabad-abad lampau bahkan menjadi daerah awal penyebaran Islam dibandingkan dengan daerah pedalaman. Dengan kata lain, budaya Arek telah menjadi keraton/benteng pusat peradaban Islam di Jawa. Hal ini memiliki konsekuensi nilai-nilai Islam pada budaya arek sangat erat melekat, salah satu pengaruh nilai tersebut dapat dijumpai pada kode busana yang ditampilkan pada wujud boneka wayang Jekdong terutama pada boneka wayang tokoh Dewa maupun Resi.

Sebagai merupakan kesenian khas budaya Arek, wayang Jekdong yang jarang disinggung dalam konteks akademik terutama dalam ranah kesenirupaan dan desain komunikasi visual. Sebagai kesenian yang diproduksi dan dilestarikan oleh masyarakat yang jauh dari budaya konsentris keraton Jawa, menarik untuk dikaji tentang intertekstualitas kondisi sosial budaya Arek yang tercermin dalam artefak rupa boneka wayang Jekdong.

Melalui penelitian ini diharapkan dapat menambah khazanah ilmu tanda, nilai islami dan relevansinya dengan budaya visual Nusantara (Jawa Timur). Dilain sisi, penelitian ini diharapkan dapat menjadi pendorong budaya wayang Jekdong agar semakin menjadi perbincangan dalam konteks akademik seni dan desain agar keberadaan budaya wayang Jekdong tetap lestari.

\section{METODE PENELITIAN}

\subsection{Sampel Boneka Wayang}

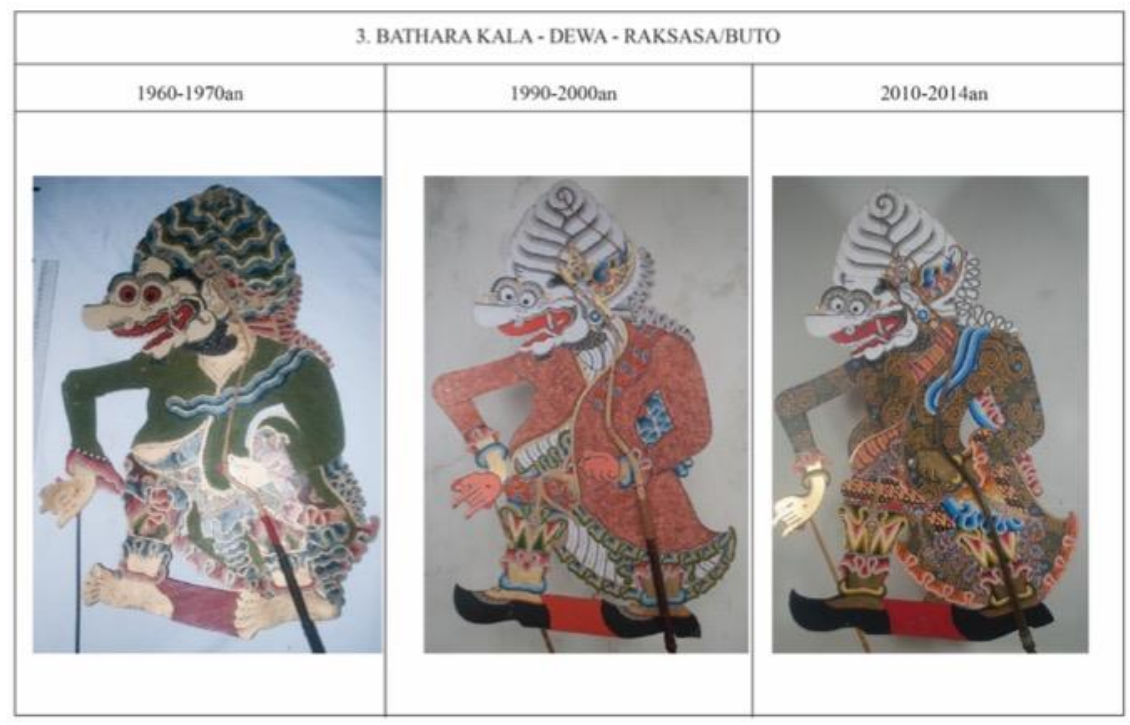

Gambar 2. Sampel wayang Bethara Kala

[Sumber: Dokumentasi Penulis]

Boneka wayang Jekdong Bethara Kala menjadi fokus utama untuk merepresentasikan fenomena di atas, terdiri dari tiga boneka wayang yang berbeda sesuai dengan periode pembuatan boneka wayang. Periode tersebut digolongkan berdasarkan 3 rentang waktu yaitu boneka dengan tahun pembuatan 1960-an, 1990-an, serta pada kisaran 2014-an. Boneka dengan rentang waktu pembuatan tahun 1990-2014-an dipilih dari koleksi Ki Wardono salah satu dalang kondang dan penyungging (pengrajin) wayang Jekdong yang 
berasal dari daerah Jiyu, kabupaten Mojokerto. Boneka wayang Bethara Kala dengan tahun pembuatan 1960-an berasal dari daerah dan koleksi pihak yang tidak dapat disebutkan (dikarenakan permintaan pemilik boneka wayang).

\subsection{Metode Analisis Rupa}

Analisis menggunakan metode analisis teks rupa. Masing-masing tanda visual akan diidentifikasi dengan relasi ketetapan boneka wayang secara utuh, dengan memperbandingkan ketiga wayang dapat diindentifikasi bagaimana pola tanda visual pada masing-masing boneka wayang dari dimensi sintagmatik dan paradigmatik untuk mempermudah proses analisis, proses analisis tanda visual akan menggunakan beberapa langkah metode etnografi analisis komponen dari James P. Spradley (Spradley, 2007: 245-247) yang didukung analisis semiotika dyadic dari Saussure dan Barthes dalam membedah pemaknaan tanda visual. Analisis komponen yang dikemukakan olah Spradley dilakukan dengan mencari dengan sistematis berbagai atribut yang berhubungan simbol-simbol budaya. Dalam hal ini adalah komponen-komponen rupa boneka wayang yang akan dibahas meliputi hanya meliputi penanda busana beserta atribut yang ditampilkan pada boneka wayang Jekdong.

\section{HASIL DAN PEMBAHASAN}

\subsection{Busana Bagian Kepala.}

Pilihan paradigma tanda pakaian juga merepresentasikan figur bethara Kala sebagai dewa. Boneka wayang bethara Kala ditampilkan memiliki kelengkapan busana yang lengkap menutupi setiap bagian tubuh wayang mulai dari kepala hingga telapak kaki.

Pada bagian kepala, terdapat penanda bidang yang menyerupai garis-garis tersusun menutupi bagian atas kepala. Bentuk yang demikian memiliki kesamaan dengan bentuk sorban atau masyarakat dalang Jekdong, adapula yang mengistilahkan dengan istilah destar. Tradisi busana penutup kepala berupa ikatan kain pada masyarakat Jawa telah lama ada dalam masyarakat Jawa (Noerhadi, 2012: 13-15)(Raffles, 2016: 52)(Ponder, 1988: 21). Namun, penutup kepala jenis ini dibentuk dari struktur kain yang berukuran kotak dan bermotif batik. Sedangkan untuk membentuk struktur gulungan kain pada penanda sorban seperti pada rupa wayang Bethara Kala lebih menyerupai bentukan seperti sorban gaya arab yang mempunyai sisa kain sorban memanjang pada bagian belakang kepala.

Penutup kepala seperti ini tampak pula seperti yang dikenakan oleh pangeran Diponegoro dalam era perang Jawa seperti yang djelaskan oleh Payen (Carey, 2016: 295) yang mengenakan busana putih bergaya Arab lengkap dengan sorban ketika masa perang Jawa yang dikobarkannya. Raffles menjelaskan pula tentang sorban bergaya arab umum digunakan oleh para ulama Jawa beserta pakaian arabnya (Raffles, 2016).

Deskripsi sorban bergaya arab tidaklah begitu spesifik mengingat ada beberapa tipe sorban yang berbeda-beda sesuai dengan budaya masing-masing daerah. Deskripsi sorban bergaya arab lebih dekat dengan deskripsi penutup kepala masyarakat arab yang disebut dengan 'imama (عِمَامَة). 'Imama merupakan salah satu bentuk penutup kepala masyarakat Muslim sejak awal agama Islam berdiri. 'Imama pada awalnya lanjut 
penjelasan Meri terdiri atas secarik potongan kain sederhana yang dibelitkan menutupi atas kepala (Meri, 2006: 159). Dalam perkembangannya bentuk, 'imama diharuskan terdiri dari potongan kain yang sangat panjang yang dapat menjadi kain serbaguna untuk membalut luka disaat genting (Stillman, 2003: 8).

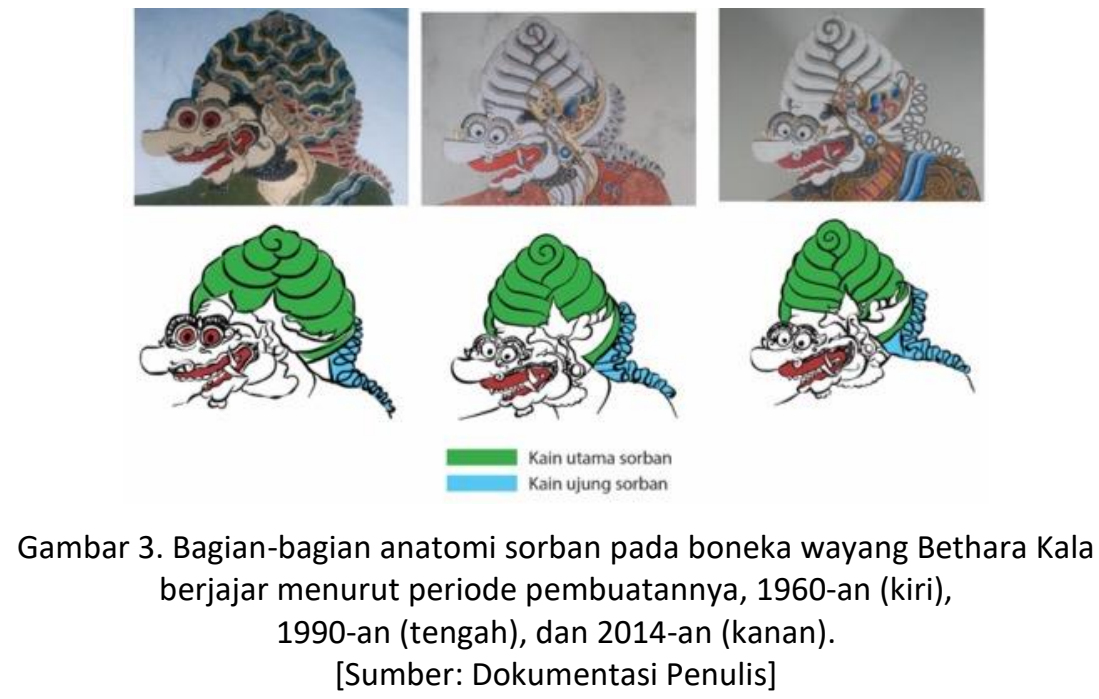

Sorban/turban sangat populer sebagai identitas seorang Muslim dan sangat dihormati keberadaanya (Jirousek, 2004). Fenomena tersebut mungkin dapat dikarenakan terkait erat keberadannya dengan figur legendaris dalam Islam, yaitu sebagai bagian busana dari nabi Muhammad SAW yang dikenal dengan julukan sahib al-'imama (sang pemakai sorban)(Meri, 2006). Masyarakat muslim menganggap sorban adalah "badge of Islam" (sima al-Islam) lencana Islam yang membedakan antara Muslim dengan yang bukan, bahkan lanjut Stillman penggunaan 'imama hanya dapat secara eksklusif dipakai oleh ulama di Timur Tengah sampai pada Magribi, terutama di Maroko (Stillman, 2003: 17).

Terdapat perbedaan visualisasi sorban pada ketiga boneka wayang Bethara Kala, perbedaan tersebut dalam ukuran/bentuk dan warna. Pada sampel tahun 1960-an memiliki bentuk lebih membulat sehingga memiliki kesan lilitan kain yang lebih panjang, sementara pada sampel tahun 1990 dan 2014-an ditampilkan dengan kesan lebih mengerucut. Perbedaan tersebut tidak merubah esensi dari bentuk kain sorban yang terdiri dari struktur lilitan kain. Perbedaan mencolok lainnya ada pada segi pewarnaan penanda visual sorban, wayang tahun 1960-an menampilkan penanda sorban dengan pewarnaan yang lebih beragam dengan kombinasi warna hijau tua-hijau, muda-putih, biru muda dengan bagian ekor divisualisasikan menggunakan warna analogus merah dominan. Sementara pada boneka wayang tahun 1990 dan 2014-an dominasi warna adalah putih baik pada kain utama sorban maupun pada ujung kain dan dengan sedikit aksen abu-abu untuk mengesankan bayangan. Warna putih yang dominan pada boneka wayang Jekdong tidak hanya ditemukan pada boneka wayang Bethara Kala tampak setiap visualisasi warna penanda sorban untuk setiap boneka wayang yang mengenakannya memiliki kombinasi warna dominan putih yang serupa. Dominasi warna putih pada sorban tersebut tampak jelas pada simpingan kanan saat pagelaran wayang. 
Penanda warna putih pada sorban tampak begitu penting ditampilkan berulang-ulang pada boneka wayang Jekdong. Hal berkaitan dengan pesan makna konotasi tanda yang berkaitan pada nilai-nilai Islami yang dibawakan oleh penanda sorban tersebut. Keistimewaan warna putih dalam masyarakat Islam, argumen ini menurut Stillman dilandasi dari beberapa hadist riwayat nabi Muhammad SAW yang mengatakan bahwa 'pakaian terbaik anda adalah yang berwarna putih' serta Hadist yang tidak terkanonisasi menyebutkan bahwa 'Allah SWT menyukai pakaian berwarna putih dan ia menciptakan surga putih' (Stillman, 2003:30). Selain itu dalam aturan ritual berhaji memiliki aturan mengenakan pakaian khusus dengan warna putih yang disebut dengan pakaian 'Ihram' yang berarti ritual kesucian (Cornell, 2007: 29). Tampak bahwa makna warna putih lebih dekat dengan pesan-pesan keilahian dan kesucian seperti yang diteladankan oleh nabi Muhammad SAW.

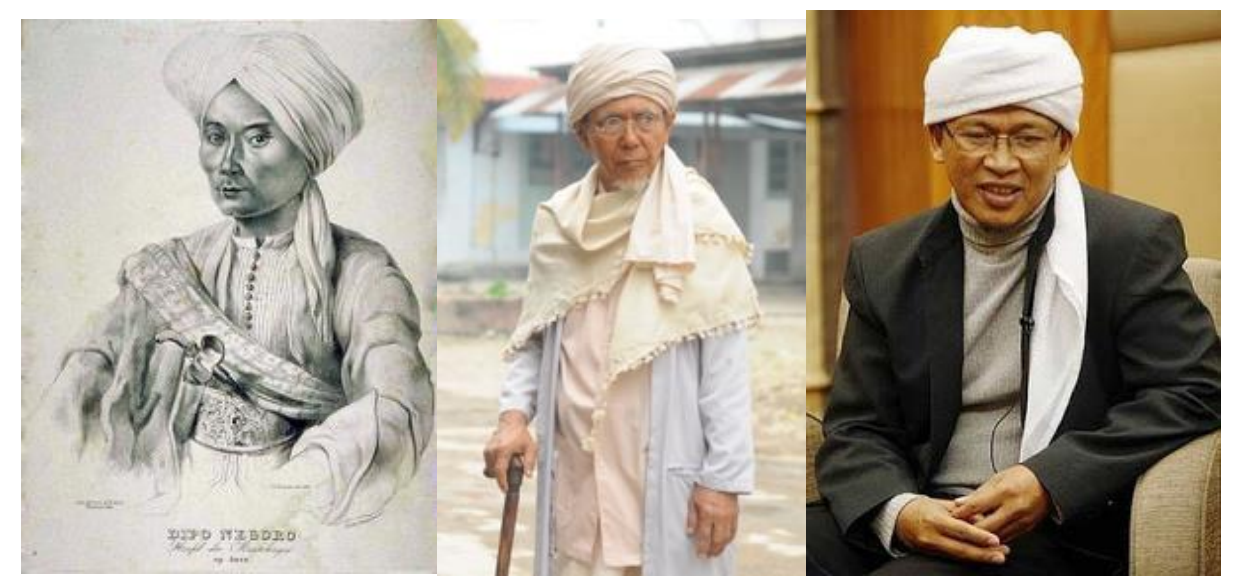

Gambar 4. Sorban/'imama yang dikenakan pada Pangeran Diponegoro (kiri), Kyai Hasyim Ashari yang diperankan oleh Ikranagara (tengah), dan Abdullah Gymnastiar (kanan).

[Sumber: https://upload.wikimedia.org/, http://4.bp.blogspot.com]
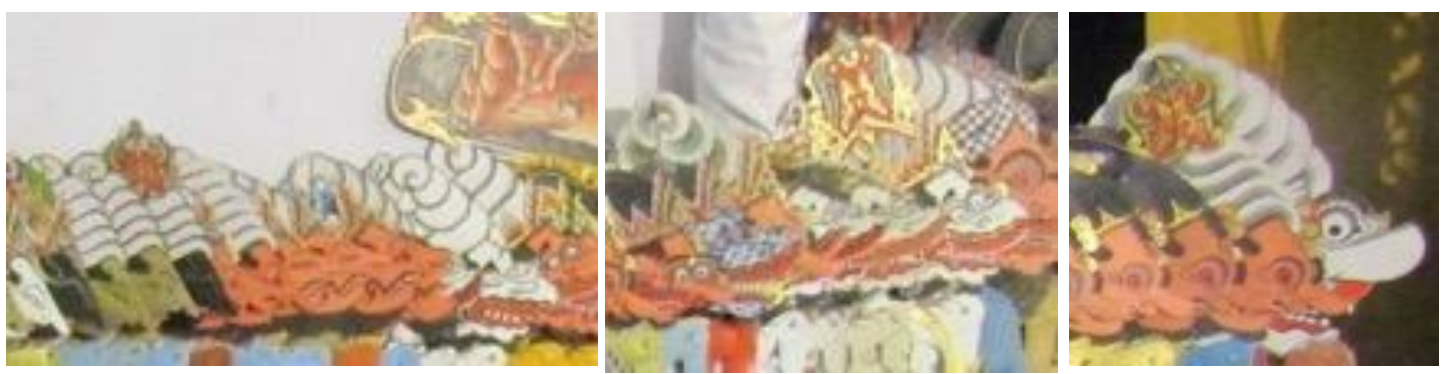

Gambar 5. Penanda-penanda sorban/'imama yang dominan putih pada Wayang Jekdong [Sumber: Dokumentasi penulis]

Melalui visualisasi sorban berwarna putih menyampaikan mitos bahwa figur Bethara Kala merupakan figur yang dekat dengan nilai-nilai keilahian yang suci. Penyampaian pesan tersebut dilakukan dengan meminjam penanda sorban/'imama untuk mengakomodasi nilai-nilai Islam yang kental pada masyarakat budaya Arek. 


\subsection{Busana Tubuh Atas}

Penanda visual busana atas terdiri dari busana sepanjang mata kaki yang menutup tubuh bagian atas dan lengan hingga pergelangan yang disebut dengan Jubah. Kecuali pada boneka wayang tahun 1960-an tampak direpresentasikan pada visual busana panjang tersebut melapisi busana yang berada lebih di dalam. Hal ini diindikasikan terdapat perbedaan motif pada bagian-bagian yang tidak tertutup oleh busana panjang ini seperti bagian leher dan perut.
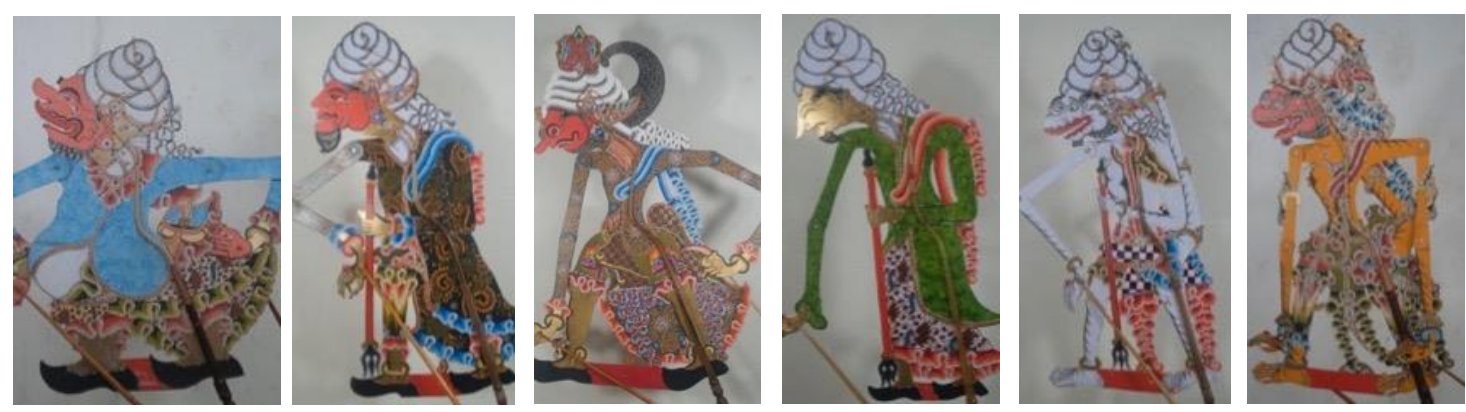

Gambar 6. Boneka wayang golongan Dewa dan Resi tahun pembuatan 2014-an yang mengenakan atribut busana Arab/Timur Tengah

[Sumber: Dokumentasi penulis]

Diperkirakan busana jenis ini terinspirasi secara sintagmatik oleh kode busana masyarakat asing terutama yang berasal dari daerah Timur Tengah, dikarenakan sistem busana masyarakat Jawa kuno tidak memiliki sistem lapisan/layering busana atas seperti yang tampak pada visual boneka wayang Bethara Kala. Sintagmatik kode busana masyarakat Jawa kuno cenderung tidak memiliki sistem busana yang rumit pada bagian badan atas, kelengkapan kain busana cenderung dititik-beratkan untuk menutup badan bagian bawah (Noerhadi, 2012: 27). Sistem busana atas yang berlapis dalam pemakaiannya dapat ditemukan pada sistem busana daerah Timur Tengah, seperti yang dijelaskan oleh Jirousek (2005), yang menyatakan bahwa sistem layering/lapisan-lapisan busana dalam budaya Turki sangatlah mengandung nilai estetik yang penting. Jenis pakaian berlapis-lapis seperti ini pun tidak dimiliki oleh masyarakat Arab awal. Busana masyarakat Arab mulanya berupa kain tidak terjahit yang dililitkan pada tubuh. Penggunaan pakaian yang telah disesuaikan dan dijahit pada masyarakat Arab dipengaruhi sistem busana peradaban sekitarnya seperti Persia dan Turki (Stillman, 2003: 47-50).

Sistem lapisan busana masyarakat Arab umumnya terdiri atas pakaian lapisan pertama dan dilapisi oleh pakaian luar yang berfungsi sebagai mantel (Jirousek, 2004). Pola seperti ini dijelaskan oleh Stillman telah ada sejak zaman nabi Muhammad SAW dimana pakaian dasar yang disebut dengan Qamis yang kemudian dilapisi oleh beragam jubah dan tunik (Stillman, 2003: 55-57). Semakin tebal lapisan-lapisan baju menunjukkan kekayaan dan status sosial pemakai yang tinggi (Jirousek, 2005). Umumnya masyarakat dengan status sosial rendah mengenakan busana yang lebih pendek daripada kalangan elit, dicontohkan oleh Stillman seperti pekerja menggunakan jubah hanya sepanjang lutut. Pengaruh tata busana masyarkat Turki dan Persia pada akhirnya membawa bentuk jubah yang dikenal oleh masyarakat Arab dengan sebutan Khaftan (Stillman, 2003: 138). 
Khaftan menurut penjelasan Stillman dikenalkan pada dinasti Abbasiah, pakaian ini berbentuk jubah panjang dengan lengan baju yang memiliki kancing didepan. Diperkirakan pada era modern jubah Arab yang disebut dengan Bishts juga dipengarui oleh model Khaftan (Al-Mukhtar, 2012).

Penjelasan mengenai berbagai busana Arab di atas memberikan petunjuk tentang jenis pakaian yang divisualisasikan pada ketiga sampel boneka wayang Bethara Kala, dimungkinkan merujuk pada pola-pola pakaian masyarakat Timur Tengah yang dipakai berdasarkan kode lapisan-lapisan pakaian. Representasi penanda keislaman diwakili oleh tanda pakaian panjang pada boneka wayang Bethara Kala mempunyai kemiripan dengan bentuk jubah masyarakat Timur Tengah khususnya Khaftan. Penggunaan pola pakaian Khaftan beserta vestimentary system yang dimiliknya pada rupa boneka wayang Bethara Kala dapat dimengerti dalam rangka membangun petanda visual identitas status sosial figur Bethara Kala dengan meminjam kode cara berpakaian masyarakat Timur Tengah khususnya masyarakat muslim Arab. Panjangnya jubah Khaftan hingga sampai ke mata kaki (boneka wayang tahun 1960-2014-an) dan terdapatnya lapisanlapisan baju (1990-2014-an) mengindikasikan pesan derajat sosial yang tinggi pada figur Bethara Kala sebagai golongan Dewa. Kondisi demikian digunakan untuk membangun mitos kesucian atau yang bersifat keillahian yang dihadirkan melalui visual busana Timur Tengah dalam boneka wayang Bethara Kala.

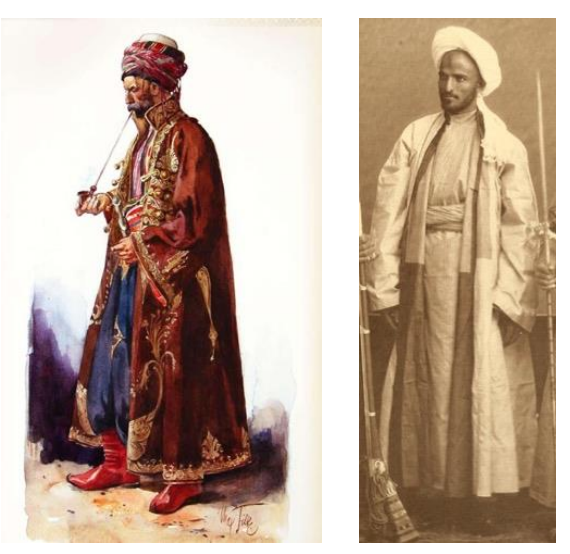

Gambar 7. Lukisan seorang Suku Kurdi mengenakan Khaftan Karya Max Karl Tilke, dan potret seorang Ulama dari Mekah pada Tahun 1873.

[Sumber: Jirousek, 2004 \& https://en.wikipedia.org/]

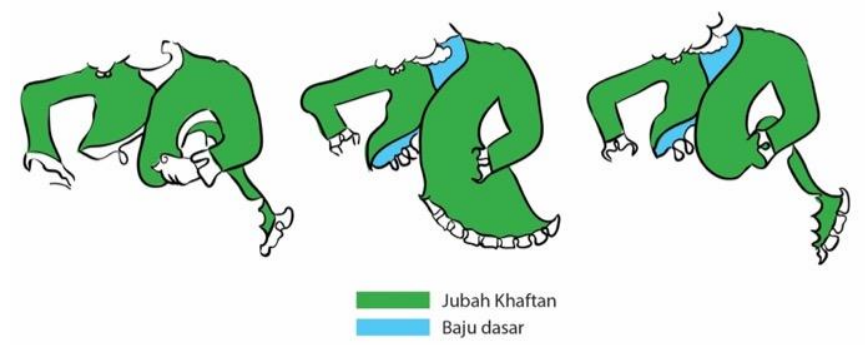

Gambar 8. Anatomi pakaian yang berlapis pada Boneka Wayang Bethara Kala berjajar menurut periode pembuatannya, 1960-an (kiri), 1990-an (tengah), dan 2014-an (kanan).

[Sumber: Dokumentasi penulis] 


\subsection{Busana Tubuh Bawah dan Perlengkapan Kaki}

Pada busana bagian tubuh bawah tampak menggunakan penanda visual sistem pakaian Jawa dengan kelengkapan kain Dodot beserta penggambaran liukan wiru, celana panjang dengan motif segitiga berulang, dan juga sepatu (pada boneka wayang 1990 hingga 2014-an). Terdapat beberapa perbedaan visual pada bagian Dodot dan juga pada bagian sepatu. Pada bagian kain Dodot perbedaan yang tampak terdapat pada ragam hias yang digunakan, boneka wayang 1960 dan 1990-an menggunakan ragam hias yang berbentuk motif bunga menyebar di seluruh bidang kain dodot, sedangkan pada sampel boneka tahun 2014-an menggunakan motif yang menyerupai motif parang rusak. Umumnya pada hampir seluruh boneka wayang Jekdong penanda kain penutup tubuh bawah menggunakan motif bunga sebagai isian, sedangkan pada sampel boneka wayang Bethara Kala menggunakan motif parang rusak. Penanda motif parang rusak menurut Alit Veldhuisen (dalam Noerhadi, 2012: 27), memiliki petanda yang merupakan salah satu motif yang dikhususkan dipakai secara eksklusif untuk keluarga raja dan raja sendiri. Maka dapat disimpulkan bahwa penanda motif parang rusak yang ditempatkan pada penanda kain dodot boneka wayang Bethara Kala tahun 2014. Petanda motif parang rusak mempertegas pesan status kedudukan sosial yang sejajar atau melebihi kedudukan dari raja.
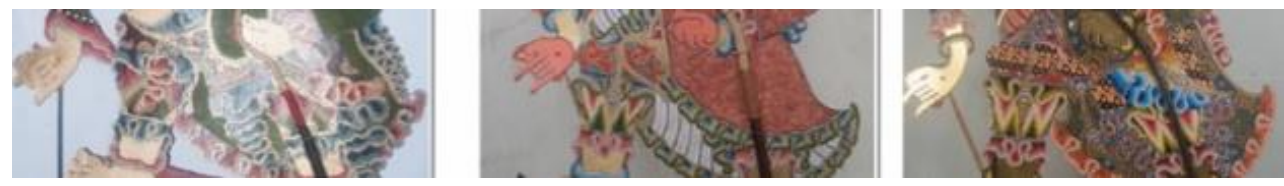

Gambar 9. Penanda visual motif segitiga (tumpal) yang nampak konsisten dipertahankan di celana boneka Wayang Jekdong, serta motif pada dhodot (di atas Celana) yang tidak konsisten pada dua periode boneka wayang. 1960-an (kiri), 1990-an (tengah), dan 2014-an (kanan).

[Sumber: Dokumentasi Penulis]

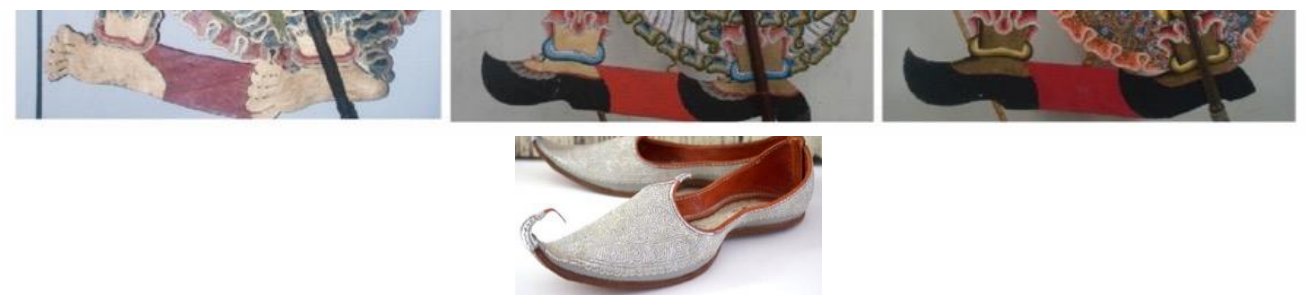

Gambar 10. Bentuk alas kaki yang menyerupai sepatu Persia pada boneka Wayang Bethara Kala berjajar menurut periode pembuatannya, 1960-an (Kiri), 1990-an (Tengah), dan 2014-an (Kanan).

[Sumber: https://i.pinimg.com/ ]

Perbedaan selanjutnya adalah pada penanda visual sepatu yang hanya ditemukan pada boneka wayang Bethara Kala sampel tahun 1990 dan 2014-an, sedangkan pada tahun 1960-an tidak diperlihatkan memakai alas kaki apapun. Tanda alas kaki yang berbentuk seperti sepatu pada masyarakat Jawa Kuno jarang ditemukan contoh kasus seperti pada relief Karmawibhilangga (Noerhadi, 2012: 64), bentuk alas kaki seperti pada sampel boneka wayang Bethara Kala membentuk kerucut pada ujung jari yang menyerupai bentuk perahu (yang populer dengan istilah persian slipper) diduga dipengaruhi dari budaya Timur Tengah dan Asia Tengah. Jika diselaraskan dengan bentuk paradigma 
busana bethara Kala maka dapat disimpulkan meminjam kode busana yang sama yaitu bagian busana Turki/Persia.

Pada bagian visual celana senantiasa mempertahankan motif yang menyerupai tumpal yang khas selalu ada sebagai bagian dari motif yang selalu ada pada celana boneka wayang Jekdong yang memiliki atribut tersebut. Tanda motif ini penting untuk dihadirkan secara konsisten dikarenakan telah dianggap sebagai motif khas yang ada pada wayang Jekdong. Motif tumpal tersebut sebenarnya telah ada sejak jaman kerajaan Hindu-Budha yang diindikasi memiliki makna sebagai mandala triloka (tiga dunia), namun lambat laun motif tersebut semakin erat dikaitkan sebagai bagian budaya masyarakat pesisir yang didominasi oleh rakyat jelata.

Penanda perhiasan pada boneka wayang Bethara Kala memiliki kelengkapan yang relatif lengkap. Hal itu dapat terlihat pada perhiasan bagian kepala mengenakan perhiasan berupa sumping dan anting-anting/giwang. Pada bagian pergelangan tangan (kecuali sampel 1960-an) dan kaki ditampakkan menggunakan gelang pada masing-masing pergelangan. Kelengkapan perhiasan dan kelengkapan pakaian yang menutupi setiap anggota tubuh menyampaikan pesan konotatif yang kuat tentang kedudukan figur Bethara Kala sebagai seorang yang berkedudukan tinggi (Dewa). Menjadi unik diperhatikan adalah cara-cara penyampaian kedudukan tinggi tersebut melalui pilihanpilihan sistem kode busana yang berbeda yaitu menggabungkan sistem tanda busana masyarakat Arab-Turki-Persia melalui kelengkapan lapisan pakaian dan jubah panjangnya pada tubuh bagian atas serta sistem tanda busana masyarakat Jawa pada tubuh bagian bawah dan sistem perhiasan. Hal ini menggambarkan bagaimana kondisi dan karakter nilai-nilai masyarakat tempat kebudayaan wayang Jekdong berada.

\section{KESIMPULAN}

Boneka wayang Jekdong sebagai artefak masyarakat budaya Arek senantiasa mencerminkan nilai-nilai sosio-kultural masyarakat pelaku budayanya. Masyarakat budaya Arek dalam konteks dakwah Islam menjadi salah satu wilayah yang paling awal bersinggungan dengan nilai-nilai Islam yang berasal dari luar Jawa.

Keterikatan yang kuat nilai-nilai kebudayaan Islam pada masyarakat penonton wayang Jekdong yang secara dominan sebagai Muslim. Wilayah budaya Arek yang umumnya masih dalam lingkup pesisir telah lama mengalami proses islamisasi yang kental dibandingkan area pedalaman seperti keraton Solo/Yogyakarta. Hal ini menyebabkan nilai-nilai Islam lebih kuat mengakar pada masyarakat budaya Arek.

Dalam kaitannya dengan tradisi perupaan boneka wayang Jekdong, nilai-nilai Islami yang erat dengan budaya Arab dan Timur Tengah turut mempengaruhi bentuk rupa. Upaya peminjaman sistem tanda dari budaya-budaya tersebut dapat dilihat pada boneka wayang Bethara Kala melalui penanda-penanda pakaian budaya Arab dan Timur-Tengah untuk mempermudah penyampaian pesan-pesan sifat dan latar belakang figur Dewa maupun Resi yang digambarkan sebagai golongan dengan derajat tertinggi dalam dunia pewayangan Jawa Timur. 


\section{DAFTAR PUSTAKA}

Aizid, R. (2015). Islam Abangan \& Kehidupannya: Seluk-Beluk Kehidupan Islam Abangan. Dipta.

Anshori, Y., \& Kusrianto, A. (2011). Keeksotisan Batik Jawa Timur. Elex Media Komputindo.

Carey, P. (2016). Takdir Riwayat Pangeran Diponegoro, 1785-1855. Penerbit Buku Kompas.

Christianto, W. N. (2012). Jek-Dong: The Enforcer of Social Bond. Jurnal Humaniora, 24(2), 175-186.

Cornell, V. (2007). Voices of Islam. Praeger Publishers.

Jirousek, C. (2004). "Islamic Clothing." In Encyclopedia of Islam. Macmillan Pub.

Jirousek, C. (2005). From Ottoman Costumes: From Textile to Identity. Eren Publishing.

Meri, J. W. (2006). Medieval Islamic civilization: An encyclopedia. Routledge Taylor \& Francis Group.

Noerhadi, I. C. (2012). Busana Jawa Kuna. Komunitas Bambu.

Ponder, H. W. (1988). Java Pageant: Impressions of the 1930s. Oxford University Press. Raffles, Thomas. S. (2016). The History of Java. Narasi.

Ricklefes, M. C. (2016). Sejarah Indonesia modern (11th ed.). Gadjah Mada University Press.

Spradley, J. P. (2007). Metode Etnografi (M. Elizabeth, Trans.; 2nd ed.). Tiara Wacana.

Stillman, Y. K. (2003). Arab dress: From the dawn of Islam to modern times. Brill.

Syam, N. (2005). Islam Pesisir. LKiS.

Sumber Gambar:

https://upload.wikimedia.org/wikipedia/commons/thumb/2/2c/Diponegoro.jpg/451p x-Diponegoro.jpg, diakses 15 Mei 2018, 12.45 Wib

http://4.bp.blogspot.com/-ynTGxnz_Tvl/UZyfeCjIS4I/AAAAAAAABJk/PIbSRr88I1s /s1600/Sang-Kiai-001.JPG, diakses 15 Mei 2018, 12.45 Wib

https://4.bp.blogspot.com/-6ihbxzMKX3Y/V288XN5IIsl/AAAAAAAADBM/ Ml9fGmIJIEf9tBAJpED6jpYvAq9icYbwCLcB/s320/kumpulan\%2Bfoto\%2Baa\%2Bgym\%2B \%25282\%2529.jpg, diakses 15 Mei 2018, 12.45 Wib

https://en.wikipedia.org/wiki/Ottoman_clothing\#/media/File:Les_costumes_populaire s_de_la_Turquie_en_1873_-_Partie_3_-_Planche_039.jpg, diakses 21 Juli 2018, 16.24 Wib

https://i.pinimg.com/originals/54/a7/f2/54a7f27994b65092fc15d3eb04a92f65.jpg, diakses 26 Juni 2018, 18.00 Wib 